\title{
Clear cell carcinoma of the ovary: Is there a role of histology-specific treatment?
}

\author{
Masashi Takano ${ }^{1 *}$, Hiroshi Tsuda² and Toru Sugiyama ${ }^{3}$
}

\begin{abstract}
Several clinical trials to establish standard treatment modality for ovarian cancers included a high abundance of patients with serous histologic tumors, which were quite sensitive to platinum-based chemotherapy. On the other hand, ovarian tumor with rare histologic subtypes such as clear cell or mucinous tumors have been recognized to show chemo-resistant phenotype, leading to poorer prognosis. Especially, clear cell carcinoma of the ovary (CCC) is a distinctive tumor, deriving from endometriosis or clear cell adenofibroma, and response rate to platinum-based therapy is extremely low. It was implied that complete surgical staging enabled us to distinguish a high risk group of recurrence in CCC patients whose disease was confined to the ovary (pT1M0); however, complete surgical staging procedures could not lead to improved survival. Moreover, the status of peritoneal cytology was recognized as an independent prognostic factor in early-staged CCC patients, even after complete surgical staging. In advanced cases with CCC, the patients with no residual tumor had significantly better survival than those with the tumor less than $1 \mathrm{~cm}$ or those with tumor diameter more than $1 \mathrm{~cm}$. Therefore, the importance of achieving no macroscopic residual disease at primary surgery is so important compared with other histologic subtypes. On the other hand, many studies have shown that conventional platinum-based chemotherapy regimens yielded a poorer prognosis in patients with CCC than in patients with serous subtypes. The response rate by paclitaxel plus carboplatin (TC) was slightly higher, ranging from $22 \%$ to $56 \%$, which was not satisfactory enough. Another regimen for CCC tumors is now being explored: irinotecan plus cisplatin, and molecular targeting agents. In this review article, we discuss the surgical issues for early-staged and advanced CCC including possibility of fertility-sparing surgery, and the chemotherapy for CCC disease.
\end{abstract}

Keywords: Review, Ovarian cancer, Clear cell carcinoma, Surgical staging, Fertility-sparing, Chemotherapy, Molecular targeting agents

\section{Background}

Clear cell adenocarcinoma (CCC) is a distinct entity from other epithelial ovarian carcinomas (EOC). CCC is thought to arise from endometriosis or clear cell adenofibroma, however, the origin of serous cyst adenocarcinoma (SCA) is thought to be Mullerian epithelium derived from either ovarian surface epithelium or fallopian tube (endosalpingiosis). CCC has specific biological and clinical behavior, compared with other histological types. However, in the studies used as evidence for recommended treatment as standard treatment of EOC, most of the enrolled patients were not clear cell

\footnotetext{
*Correspondence: mastkn@ndmc.ac.jp

'Department of Obstetrics and Gynecology, National Defense Medical College, Tokorozawa, Saitama 359-8513, Japan

Full list of author information is available at the end of the article
}

histology, and these study results do not provide a scientific rationale for CCC. In this review, we summarize the treatment of CCC.

\section{Surgical treatment}

The standard surgical treatment of patients with EOC is based on hysterectomy, bilateral salpingo-oophorectomy and partial omentectomy with peritoneal sampling and lymphadenectomy, and cytoreductive surgery is added especially for advanced cases. The surgical treatment of CCC is usually determined based on the guideline of EOC. In this section, we summarize the surgical treatment of CCC patients.

\section{Surgical staging}

It has been reported that the incidence of lymph node metastasis in stage I (pT1) EOC was approximately 5-

\section{Biomed Central}


Table 1 Rates of lymph node metastasis in early-staged clear cell carcinoma and serous adenocarcinoma

\begin{tabular}{|c|c|c|c|c|}
\hline author & year & $\begin{array}{l}\text { number of } \\
\text { patients }\end{array}$ & pT stage & metastatic rate \\
\hline \multicolumn{5}{|c|}{ clear cell carcinoma } \\
\hline Di Re[2] & 1989 & 11 & pT1 & $9 \%(1 / 11)$ \\
\hline Petru[3] & 1994 & 2 & pT1 & $0 \%(0 / 2)$ \\
\hline Onda[4] & 1996 & 16 & $\mathrm{p} T 1 / 2$ & $31 \%(5 / 16)$ \\
\hline Baiocchi[5] & 1998 & 21 & pT1 & $5 \%(1 / 21)$ \\
\hline Suzuki[6] & 2000 & 9 & pT1 & $11 \%(1 / 9)$ \\
\hline Sakuragi[7] & 2000 & 23 & $\mathrm{pT} 1 / 2$ & $17 \%(4 / 23)$ \\
\hline \multirow[t]{2}{*}{ Negishi[8] } & 2004 & 46 & pT1 & $12 \%(5 / 42)$ \\
\hline & & & pT2 & $75 \%(3 / 4)$ \\
\hline \multirow[t]{3}{*}{ Takano[9] } & 2006 & 173 & pT1a & $9 \%(3 / 36)$ \\
\hline & & & pT1c & $7 \%(7 / 99)$ \\
\hline & & & pT2 & $13 \%(5 / 38)$ \\
\hline Harter[10] & 2007 & 7 & pT1 & $0 \%(0 / 7)$ \\
\hline Desteli[11] & 2010 & 4 & pT1 & $0 \%(0 / 4)$ \\
\hline Nomura[12] & 2010 & 36 & $\mathrm{p} T 1 / 2$ & $6 \%(2 / 36)$ \\
\hline Subtotal & & 348 & & $11 \%(37 / 348)$ \\
\hline \multicolumn{5}{|c|}{ Serous cystadenocarcinoma } \\
\hline Di Re[2] & 1989 & 40 & pT1 & $28 \%(11 / 40)$ \\
\hline Petru[3] & 1994 & 21 & $\mathrm{pT} 1$ & $38 \%(8 / 21)$ \\
\hline Onda[4] & 1996 & 21 & $\mathrm{pT} 1 / 2$ & $33 \%(7 / 21)$ \\
\hline Baiocchi[5] & 1998 & 106 & pT1 & $26 \%(27 / 106)$ \\
\hline Suzuki[6] & 2000 & 13 & pT1 & $31 \%(4 / 13)$ \\
\hline Sakuragi[7] & 2000 & 25 & $\mathrm{p} T 1 / 2$ & $8 \%(2 / 25)$ \\
\hline Morice[13] & 2003 & 26 & pT1 & $31 \%(8 / 26)$ \\
\hline \multirow[t]{2}{*}{ Negishi[8] } & 2004 & 35 & pT1 & $4 \%(1 / 24)$ \\
\hline & & & pT2 & $36 \%(4 / 11)$ \\
\hline Harter[10] & 2007 & 13 & pT1 & $15 \%(2 / 13)$ \\
\hline Desteli[11] & 2010 & 7 & $\mathrm{pT} 1$ & $14 \%(1 / 7)$ \\
\hline Nomura[12] & 2010 & 12 & $\mathrm{pT} 1 / 2$ & $50 \%(6 / 12)$ \\
\hline Subtotal & & 319 & & $25 \%(81 / 319)$ \\
\hline
\end{tabular}

$20 \%$ [1-6]. Reported rates of lymph node metastasis in $\mathrm{CCC}$ and serous cystadenocarcinoma (SAC) were summarized in Table 1 [2-14]. From the results investigating a large number of CCC cases, retroperitoneal lymph node metastasis was observed in $9 \%$ in pTIa tumors, $7 \%$ in pTIc tumors, and $13 \%$ in pT2 tumors in CCC, which suggested that incidence of lymph node metastasis in CCC was lower than that of SAC [9]. Based on the subtotal of reported cases with pT1 and pT2 tumors, approximately one half incidence of lymph node metastasis in CCC in comparison with SAC was confirmed: $11 \%$ in CCC, and $25 \%$ in SAC.

Lymphadenectomy is so important to detect metastatic lymph nodes, as the patients with positive lymph nodes had poorer prognosis. However, the role of lymphadenectomy remains unclear based on the therapeutic aspect. Several authors reported that lymph node metastasis is independent prognostic factor for CCC $[7,8,15]$. Magazzino et al. analyzed 240 CCC retrospectively and reported as followed [15]: (1) Of 240 cases, $47.9 \%$ had lymphadenectomy and most of cases received platinum based chemotherapy after primary surgery. (2) The cases who received lymphadenectomy had longer progressionfree survival (PFS) than the cases who had no lymphadenectomy in stage I/II, III/IV and all stage $(\mathrm{p}=0.0258$, $\mathrm{p}=0.00337, \mathrm{p}=0.0001$ ). (3) In advanced cases, lymphadenectomy prolonged the overall survival (OS). (4) In CCC, lymphadenectomy and clinical stage are independent prognostic factors by multivariate analysis. However, we reported that $\mathrm{pN}$ status showed only a marginal significance upon PFS and no significance upon OS based on the analysis of 199 CCC [16]. Other reports failed to show the usefulness of lymphadenectomy as prognostic factor $[17,18]$. Further examination will be required to confirm the role of lymphadenectomy for CCC.

In our studies, multivariate analysis revealed that peritoneal cytology status was independent prognostic factor for PFS ( $\mathrm{p}=0.04)$, but not for OS, and in addition, completion of surgical staging procedures was not a prognostic factor [16]. Higashi et al. analyzed 224 CCC patients with stage I and reported as followed [19]: (1) there was no significant difference in both OS and PFS of CCC between stage IA and IC (intraoperative capsule rupture), and the 5-year OS rate of stage IC(intraoperative capsule rupture) $\mathrm{CCC}$ patients was comparable to those with the non-CCC. (2) Stage IC CCC patients except for IC (intraoperative capsule rupture), such as positive ascites/washing and capsule surface involvement, had a poorer OS and PFS than those with IC (intraoperative capsule rupture). The results suggested stage I CCC cases other than intraoperative capsule rupture were at a considerable risk for recurrence and mortality.

Finally, the role of complete surgical staging still remains unclear for CCC. Several reports demonstrated that adjuvant chemotherapy had little impact on the survival of stage I CCC patients $[16,20]$. From these findings, complete surgical staging procedures are required at least to detect high-risk patients of recurrence; however, the extent of the surgery could not improve overall survival of CCC.

\section{Cytoreductive surgery}

Optimally cytoreduced patients of EOC were reported to show a significant survival benefit over those patients who are suboptimally debulked, and there is a significant survival advantage in patients who are able to be debulked to less than $1 \mathrm{~cm}$ of residual disease. Hoskins et al. reported that patients with clear cell and mucinous histology had poor outcome even when they had small 
residual tumor after primary surgery [21]. We previously reported that there is no significant prognostic difference between the patients with the tumor diameter less than $1 \mathrm{~cm}$ and those with the tumor diameter more than $1 \mathrm{~cm}$, and complete surgery is only the independent prognostic factor [9]. Kennedy et al. reported that among patients with advanced stage cancers (FIGO stages III and IV), CCC patients were more often optimally debulked than non-CCC patients $(60 \%$ vs. $37 \%$, $\mathrm{p}=0.033$ ) [22]. From these findings, the goal of primary surgical treatment for CCC may be complete resection.

\section{Fertility-sparing surgery}

Fertility-sparing surgery (FSS) for reproductive-age patients with EOC has been adopted for stage IA and non-clear cell histology grade 1 (G1)/grade2 (G2) according to the 2007 guidelines of the American College of Obstetrics and Gynecology (ACOG) and unilateral stage I tumor without dense adhesions showing favorable histology (ie, non-clear cell histology G1/G2) according to the 2008 guidelines of the European Society for Medical Oncology (ESMO). In Japan, stage IA tumor or unilateral stage IC tumor on the basis of intraoperative capsule rupture and favorable histology are candidate for FSS according to the 2010 guidelines of the Japan Society of Gynecologic Oncology (JSGO). These 3 guidelines commonly eliminate $\mathrm{CCC}$ for the candidate of FSS. In contrast, in the 2010 guidelines of the National Comprehensive Cancer Network (NCCN), a stage I patient with CCC is an acceptable candidate for FSS. For the patients to receive FSS, randomized study cannot be performed because of ethical aspect. In this review, we summarize the FSS for CCC based on the retrospective studies.

Schilder et al. demonstrated that no recurrence was observed among 5 patients with stage IC CCC who received FFS; however, the detail of stage or postoperative chemotherapy was not recorded [23]. Kajiyama et al. reported the clinical outcome of 10 patients with stage I CCC treated with FSS (IA:4, IC(intraoperative capsule rupture): 5, IC(positive for malignant ascites):1) and demonstrated as follow [24]: (1) Among 10 patients, 9 patients received chemotherapy after surgery, (2) one patient with IC(positive for malignant ascites) who received postoperative chemotherapy recurred. Sato et al. reported 30 patients with stage I CCC who received FFS and reported as follow [25]: (1) Among 15 IA cases, 9 cases received chemotherapy after surgery and no one recurred, (2)Among 15 IC patients, 11 patients received chemotherapy after surgery, and 2 patients (IC(intraoperative capsule rupture):2) recurred among 11 patients who received chemotherapy and 3 patients (IC(intraoperative capsule rupture):2, IC(positive for malignant ascites or surface capsule involvement):1) recurred among 4 patients who did not received chemotherapy. (3) Recurrent sites are residual ovary $(\mathrm{n}=3)$, lymph node $(\mathrm{n}=2)$, peritoneum $(\mathrm{n}=2)$ and liver $(n=1)$. (4) The 5 -year survival rate is $93.3 \%$. These data are shown in Table 2.

We summarized Kajiyama's and Sato's reports in detail: (1) Among 19 patients, 12 patients received postoperative chemotherapy and no one recurred. (2) Among 21 IC patients, 17 patients received postoperative chemotherapy, and recurrent rate of IC(intraoperative capsule rupture) and IC(positive for malignant ascites or surface capsule involvement) are $25 \%(4 / 16)$ and $40 \%(2 / 5)$. (3) Among 17 IC patients who received postoperative chemotherapy, 3 (18\%) patients recurred and among 4 IC patients who did not received chemotherapy, 3 (75\%) patients recurred.

Recently, Kajiyama et al. also analyzed the OS of 16 patients with stage I CCC who underwent FSS and compared survival with 204 patients receiving radical surgery, or 64 patients with non-CCC undergoing FSS and demonstrated that patients with CCC who underwent FSS did not show a poorer survival than non-CCC patients who underwent FSS, or those at the corresponding stage with no CCC [26].

From these findings, CCC IA patient may be candidate for FFS and postoperative chemotherapy may be useful for CCC IC patient who received FFS.

\section{Chemotherapeutic treatment}

Clear cell carcinoma (CCC) is a quite unique ovarian tumor showing resistance to platinum-based chemotherapy. The effect of the gold standard therapy for ovarian carcinomas, combination with paclitaxel and carboplatin (TC), is not satisfactory for CCC. Irinotecan hydrochloride, a topoisomerase I inhibitor, is a candidate for the treatment for CCC. Irinotecan combined with cisplatin (CPT-P) has been recognized to have an activity no less than TC for CCC. A world-wide prospective clinical study to compare CPT-P and TC as the first-line chemotherapy for CCC, GCIG/JCOG (Gynecologic Cancer Intergroup/Japanese Gynecologic Oncology Group)

Table 2 Relapse rates of clear cell carcinoma patients who received FSS

\begin{tabular}{lllcc}
\hline stage & author & year & number of patients & relapse \\
\hline \multirow{2}{*}{ Stage IA } & Kajiyama [23] & 2008 & 4 & $0 \%(0 / 4)$ \\
\cline { 2 - 5 } & Satoh [24] & 2010 & 15 & $0 \%(0 / 15)$ \\
\hline \multirow{2}{*}{ Stage IC } & total & & 19 & $0 \%(0 / 19)$ \\
\cline { 2 - 5 } & Schilder [22] & 2001 & 5 & $0 \%(0 / 5)$ \\
\cline { 2 - 5 } & Kajiyama [23] & 2008 & 6 & $17 \%(1 / 6)$ \\
\cline { 2 - 5 } & Satoh [24] & 2010 & 15 & $33 \%(5 / 15)$ \\
\hline & total & & 26 & $23 \%(6 / 26)$ \\
\hline
\end{tabular}


3017, is now ongoing. Additionally, molecular-targeting agents are evaluated for advanced or recurrent CCC. We would discuss the chemotherapeutic regimens as primary or second-line therapy for $\mathrm{CCC}$ in this review.

\section{Primary chemotherapy using cytotoxic agents}

It has been implied that $\mathrm{CCC}$ of the ovary showed resistance to conventional platinum-based chemotherapy [2729]. Recent studies have confirmed the evidence in the analysis of patients with measurable CCC. Objective response was observed in 11-27\% with conventional platinum-based regimen, whereas patients with serous adenocarcinoma (SAC) subtype showed a significantly higher response rate of 73-81\% [30-32]. A report showed survival benefit of conventional chemotherapy with paclitaxel and platinum after complete surgery in CCC patients [33]. However, the result from large series of CCC patients treated with paclitaxel and platinum showed no survival benefit compared with conventional platinum-based chemotherapy in both early and advanced cases [9]. The results suggested that TC therapy, which is commonly used for ovarian carcinoma, is not effective enough for CCC patients. Reported response rates of primary therapy for CCC are summarized in Table 3 [9,29-33].

Irinotecan hydrochloride, a semisynthetic derivative of camptothecin, has additive and synergic effects in combination with cisplatin in vitro $[34,35]$. The combination therapy with irinotecan hydrochloride and cisplatin (CPT-P) was reported to be effective for patients with various solid tumors. Especially, a large clinical trial revealed that CPT-P had significant activity for extensive small-cell lung cancer [36]. Additionally, CPT-P had been reported to be effective in first-line and second-line chemotherapy for the treatment of CCC of ovary $[37,38]$. A large retrospective analysis indicated that CPT-P had a potential therapeutic effect at least no less than TC therapy [39]. A phase II study (JGOG3014) to

Table 3 Response rates of primary chemotherapy for clear cell carcinoma

\begin{tabular}{llll}
\hline regimen & author & year & $\begin{array}{l}\text { response/ Number } \\
\text { of patients, } \\
\text { response rate }\end{array}$ \\
\hline $\begin{array}{l}\text { Conventional } \\
\text { Platinum-based }\end{array}$ & Goff [28] & 1996 & $1 / 6,17 \%$ \\
\cline { 2 - 4 } & Sugiyama [29] & 2000 & $3 / 27,11 \%$ \\
\cline { 2 - 4 } & Ho [30] & 2004 & $4 / 15,27 \%$ \\
\cline { 2 - 4 } Taxane-Platinum & Takano [9] & 2006 & $5 / 30,17 \%$ \\
\cline { 2 - 4 } & Enomoto [31] & 2003 & $2 / 9,22 \%$ \\
\cline { 2 - 4 } & Ho [30] & 2004 & $9 / 16,56 \%$ \\
\cline { 2 - 4 } & Utsunomiya [32] & 2006 & $8 / 15,53 \%$ \\
\hline Irinotecan-cisplatin & Takano [9] & 2006 & $9 / 28,32 \%$ \\
\hline
\end{tabular}

compare CPT-P and TC for first-line treatment for CCC was conducted. The study revealed that completion rate of six cycles and five-year progression-free survival was similar in both arms [40]. Interesting to note, in the patients with residual tumor less than $2 \mathrm{~cm}$, overall survival was marginally improved in CPT-P group in comparison with TC group $(\mathrm{p}=0.056)$. Subsequently, a phase III randomized study to compare CPT-P and TC as adjuvant chemotherapy for CCC is on-going (GCIG/ JGOG3017) [41]. The winner regimen will be the first regimen for histologically individualized therapy for ovarian cancers.

Another issue concerning chemotherapy for CCC is adjuvant therapy for patients with stage I disease. CCC is regarded as grade 3 tumor, and clinical guidelines recommend adjuvant chemotherapy for all patients with CCC, even at stage Ia. A large retrospective analysis of stage I CCC revealed that there were no statistical differences of progression-free survival (PFS) and overall survival (OS) between patients with chemotherapy and without chemotherapy [16]. Also, multivariate analysis showed that peritoneal cytology status $(\mathrm{p}=0.02)$ and $\mathrm{pT}$ status $(p=0.04)$ were independent prognostic factors for PFS, however, adjuvant chemotherapy was not a prognostic factor $(\mathrm{p}=0.80)$. The results suggested adjuvant chemotherapy had little impact upon survival of stage I CCC patients. Further strategy, such as a molecular targeting agent, is needed to improve survival of CCC, especially cases with positive peritoneal washing.

\section{Second-line chemotherapy for CCC}

In a large series of platinum-sensitive relapsed ovarian tumors including all histological subtypes, overall response was $54 \%$ of the patients treated with the conventional platinum-based chemotherapy, and $66 \%$ of the cases treated with paclitaxel plus platinum chemotherapy [42]. In the platinum-resistant tumors, however, response rate using anti-cancer agents usually range from 25 to $30 \%$ [43]. In the second-line or salvage settings, the response rate for recurrent or refractory CCC was extremely lower than that for other histological tumors: even in the patients with platinum-sensitive CCC disease, the response rate reported was lower than $10 \%$ $[44,45]$. So, we have summarized reported cases that achieved objective response (Table 4) [30,33,44-48].

Recently, single agent gemcitabine could be a candidate for salvage therapy for $\mathrm{CCC}$, as the authors suggested [44,48]. Other regimens that showed objective response included irinotecan/platinum, etoposide/platinum, and paclitaxel/carboplatin; however, the efficacy was limited with progression-free interval approximately 6 months. Despite importance of response, it would be more important to monitor if adverse effects of chemotherapy worsen quality of life of the patients. Among 
Table 4 Response rates of salvage chemotherapy for recurrent or refractory clear cell carcinoma

\begin{tabular}{llll}
\hline regimen & author & year & $\begin{array}{l}\text { response/ number } \\
\text { of patients, } \\
\text { response rate }\end{array}$ \\
\hline Megestrol acetate & Walailak [45] & 2001 & $2 / 10,20 \%$ \\
\hline $\begin{array}{l}\text { Cyclopshosphamide+ } \\
\text { cisplatin }\end{array}$ & Takano [46] & 2008 & $1 / 9,11 \%$ \\
\hline Irinotecan+Platinum & Sugiyama [29] & 1998 & $1 / 3,33 \%$ \\
\cline { 2 - 4 } & Takano [46] & 2008 & $2 / 15,13 \%$ \\
\hline Etoposide+Platinum & Takano [46] & 2008 & $2 / 13,15 \%$ \\
\hline Paclitaxel+Carboplatin & Utsunomiya [32] & 2006 & $3 / 13,23 \%$ \\
\cline { 2 - 4 } & Crotzer [43] & 2007 & $2 / 7,29 \%$ \\
\hline Gemcitbine & Crotzer [43] & 2007 & $1 / 9,11 \%$ \\
\cline { 2 - 4 } Yoshino [47] & 2012 & $1 / 5,20 \%$ \\
\hline Docetaxel+|rinotecan & Yoshino [47] & 2012 & $1 / 11,9 \%$ \\
\hline Temsirolimus & Takano [46] & 2011 & $1 / 5,20 \%$ \\
\hline
\end{tabular}

these reports, the longest progression-period of 14 months was obtained by Temsirolimus [47]. The observed response duration was surprisingly longer than those obtained by any cytotoxic agents so far with no serious toxicities. The report encouraged us to investigate another chemotherapeutic strategy for CCC.

From the reported cases, however, it could be concluded that CCC is a potentially extremely chemo-resistant tumor against cytotoxic agents, especially in recurrent or refractory settings. Another strategy including molecular targeting agents might be needed for the treatment of these tumors.

\section{Incorporation of molecular targeting agents for the treatment of CCC}

In the aspects of molecular characteristics as well as clinical behavior, it is hypothesized that CCC belongs to a different entity from other histological subtypes of ovarian carcinoma. First of all, the incidences of p53 mutation and p53 overexpression were much less frequent in CCC than in other histologic types of epithelial ovarian cancer $[49,50]$. On the other hand, mutation of p53 gene was quite frequent in serous subtype of ovarian cancers, and most of the alterations were missense mutations [51]. In addition to p53 status, CCC has a quite unique expression pattern of several molecules. Glutathione peroxidase 3 (GPX3) was found at levels 30-fold higher on average in CCC compared with the other ovarian cancer subtypes through studies with cDNA arrays and serial analysis of gene expression [52]. Elevated expression of GPX3 might contribute to chemoresistance phenotype, which is often observed in the patients with CCC. Another investigation using oligonucleotide microarrays reported that glutaredoxin (GLRX) and superoxide dismutase 2 (SOD2), in addition to GPX3, were highly expressed in clear cell type ovarian cancer, suggesting that high levels of these proteins relating with antioxidant function render $\mathrm{CCC}$ to be more resistant to chemotherapy [53,54].

Further, a report using oligonucleotide probe arrays showed that a transcription factor, hepatocyte nuclear factor-1 (HNF-1) was upregulated in CCC cell lines [55]. Overexpression of HNF-1 was confirmed by immunohistological staining of clinical samples. Further, overexpression of HNF-1 was observed in the specimens of borderline clear cell tumor and benign clear cell tumor [56]. The expression of HNF-1 was detected in not only atypical endometrial tissue, but also in endometriosis with degenerative and regenerative changes, suggesting that early differentiation into the clear cell lineage takes place in the endometriotic epithelium, and HNF-1 contributes to carcinogenesis of CCC.

Recently, immunohistochemical analysis showed that hypoxia-inducible factor 1 alpha (HIF-1alpha) expression levels were significantly higher in CCC than in other histological types of ovarian cancers [57]. Upstream target of HIF-1alpha, mammalian target of rapamycin (mTOR), was also reported to be up regulated in CCC [58,59], which was selected for molecular target of CCC.

There are two international collaborating studies led by Gynecologic Oncology Group (GOG) to evaluate efficacy of molecular targeting agents for CCC of the ovary $[60,61]$. It is true that there existed super-responders against molecular targeting agents in the patients with CCC. Consequently, further studies to evaluate these new drugs should include biomarker analysis to predict response or adverse effect for clinical application.

\section{Conclusions}

CCC has unique characteristics among ovarian cancers. We have to deal with the tumor using completely different techniques of treatment modality in terms with surgery and chemotherapy. Especially, we have to focus on histology-specific features of molecular pattern. We hope the day will come when CCC tumors would be easily handled by the selection of effective surgery and chemotherapy including molecular targeting agents.

\section{Abbreviations}

CCC: Clear cell adenocarcinoma; SAC: Serous cyst adenocarcinoma; EOC: Epithelial ovarian carcinomas; PFS: Progression free survival; OS: Overall survival; FSS: Fertility-sparing surgery; ACOG: American college of obstetrics and gynecology; ESMO: European society for medical oncology; JSGO: Japan society of gynecologic oncology; NCCN: National comprehensive cancer network; GCIG: Gynecologic cancer intergroup; JCOG: Japanese gynecologic oncology group; CPT-P: Irinotecan hydrochloride + cisplatin;

TC: Paclitaxel + carboplatin; GPX3: Glutathione peroxidase 3; GLRX: Glutaredoxin; SOD2: Superoxide dismutase 2; HNF-1: Hepatocyte nuclear factor-1; HIF-1: Hypoxia-inducible factor 1; mTOR: Mammalian target of rapamycin; GOG: Gynecologic oncology group.

\section{Competing interests}

The authors declare that they have no competing interests. 


\section{Author details}

'Department of Obstetrics and Gynecology, National Defense Medical College, Tokorozawa, Saitama 359-8513, Japan. ${ }^{2}$ Department of Obstetrics and Gynecology, School of Medicine, Keio University, Shinano-machi 35, Shinjuku-ku, Tokyo 160-8582, Japan. ${ }^{3}$ Department of Obstetrics and Gynecology, Iwate Medical University, Morioka, Iwate 020-8505, Japan.

\section{Authors' contributions}

Dr Takano and Dr Tsuda wrote the manuscript. Dr Takano, Dr Tsuda, and Dr Sugiyama approved it. All authors read and approved the final manuscript.

Received: 17 April 2012 Accepted: 1 June 2012

Published: 1 June 2012

\section{References}

1. Takeshima N, Hirai Y, Umayahara K, et al: Lymph node metastasis in ovarian cancer: difference between serous and non-serous primary tumors. Gynecol Oncol 2005, 99:427-431.

2. Di Re F, Fontanelli R, Raspagliesi F, et al: Pelvic and para-aortic lymphadenectomy in cancer of the ovary. Baillieres Clin Obstet Gynaecol 1989, 3:131-142

3. Petru E, Lahousen M, Tamussino $\mathrm{K}$, et al: Lymphadenectomy in stage I ovarian cancer. Am J Obstet Gynecol 1994, 170:656-662.

4. Onda T, Yoshikawa $H$, Yokota $H$, et al: Assessment of metastases to aortic and pelvic lymph nodes in epithelial ovarian carcinoma, A proposal for essential sites for lymph node biopsy. Cancer 1996, 78:803-808.

5. Baiocchi G, Grosso G, di Re E, et al: Systematic pelvic and paraaortic lymphadenectomy at second-look laparotomy for ovarian cancer. Gynecol Oncol 1998, 69:151-156.

6. Suzuki M, Ohwada M, Yamada T, et al: Lymph node metastasis in stage I epithelial ovarian cancer. Gynecol Oncol 2000, 79:305-308.

7. Sakuragi N, Yamada H, Oikawa M, et al: Prognostic significance of lymph node metastasis and clear cell histology in ovarian carcinoma limited to the pelvis (pT1M0 and pT2M0). Gynecol Oncol 2000, 79:251-255.

8. Negishi H, Takeda M, Fujimoto T, et al: Lymphatic mapping and sentinel node identification as related to the primary sites of lymph node metastasis in early stage ovarian cancer. Gynecol Oncol 2004, 94:161-166.

9. Takano M, Kikuchi Y, Yaegashi N, et al: Clear cell carcinoma of the ovary: a retrospective multicentre experience of 254 patients with complete surgical staging. Br J Cancer 2006, 94:1369-1374.

10. Harter P, Gnauert K, Hils R, et al: Pattern and clinical predictors of lymph node metastases in epithelial ovarian cancer. Int J Gynecol Cancer 2007, 17:1238-1244

11. Desteli GA, Gultekin M, Usubutun A, et al: Lymph node metastasis in grossly apparent clinical stage la epithelial ovarian cancer: Hacettepe experience and review of literature. World J Surg Oncol 2010, 8:106.

12. Nomura $H$, Tsuda $H$, Susumu $N$, et al: Lymph node metastasis in grossly apparent stages I and II epithelial ovarian cancer. Int I Gynecol Cancer 2010, 20:341-345.

13. Morice $P$, Joulie $F$, Camatte $S$, et al: Lymph node involvement in epithelial ovarian cancer: analysis of 276 pelvic and paraaortic

lymphadenectomies and surgical implications. J Am Coll Surg 2003, 197:198-205.

14. Kanazawa K, Suzuki T, Tokashiki M: The validity and significance of substage IIIC by node involvement in epithelial ovarian cancer: impact of nodal metastasis on patient survival. Gynecol Oncol 1998, 73:237-241.

15. Magazzino F, Katsaros D, Ottaiano A, et al: Surgical and medical treatment of clear cell ovarian cancer: results from the multicenter Italian Trials in Ovarian Cancer (MITO) 9 retrospective study. Int J Gynecol Cancer 2011, 21:1063-1070

16. Takano M, Sugiyama T, Yaegashi N, et al: Less impact of adjuvant chemotherapy for stage I clear cell carcinoma of the ovary: a retrospective Japan Clear Cell Carcinoma Study. Int J Gynecol Cancer 2010, 20:1506-1510

17. Chan JK, Munro EG, Cheung MK, et al: Association of lymphadenectomy and survival in stage I ovarian cancer patients. Obstet Gynecol 2007, 109:12-19.

18. Suzuki S, Kajiyama H, Shibata K, et al: Is there any association between retroperitoneal lymphadenectomy and survival benefit in ovarian clear cell carcinoma patients?. Ann Oncol 2008, 19:1284-1287.
19. Higashi M, Kajiyama H, Shibata K, et al: Survival impact of capsule rupture in stage I clear cell carcinoma of the ovary in comparison with other histological types. Gynecol Oncol 2011, 123:474-478.

20. Timmers PJ, Zwinderman AH, Teodorovic I, et al: Clear cell carcinoma compared to serous carcinoma in early ovarian cancer: same prognosis in a large randomized trial. Int I Gynecol Cancer 2009, 19:88-93.

21. Hoskins WJ, Bundy BN, Thigpen JT, et al: The influence of cytoreductive surgery on recurrence-free interval and survival in small-volume stage III epithelial ovarian cancer: a Gynecologic Oncology Group study. Gynecol Oncol 1992, 47:159-166.

22. Kennedy AW, Markman M, Biscotti CV, et al: Survival probability in ovarian clear cell adenocarcinoma. Gynecol Oncol 1999, 74:108-114.

23. Schilder JM, Thompson AM, DePriest PD, et al: Outcome of reproductive age women with stage IA or IC invasive epithelial ovarian cancer treated with fertility-sparing therapy. Gynecol Oncol 2002, 87:1-7.

24. Kajiyama H, Shibata K, Suzuki S, et al: Is there any possibility of fertilitysparing surgery in patients with clear-cell carcinoma of the ovary? Gynecol Oncol 2008, 111:523-526.

25. Satoh $T$, Hatae $M$, Watanabe $Y$, et al: Outcomes of fertility-sparing surgery for stage I epithelial ovarian cancer: a proposal for patient selection. J Clin Oncol 2010, 28:1727-1732.

26. Kajiyama $H$, Shibata $K$, Mizuno $M$, et al: Fertility-sparing surgery in patients with clear-cell carcinoma of the ovary: Is it possible?. Hum Reprod 2011, 26:3297-3302

27. O'Brien ME, Schofield JB, Tan S, et al: Clear cell epithelial ovarian cancer (mesonephroid): bad prognosis only in early stages. Gynecol Oncol 1993, 49:250-254

28. Omura GA, Brady MF, Homesley HD, et al: Long-term follow-up and prognostic factor analysis in advanced ovarian carcinoma: the Gynecologic Oncology Group experience. J Clin Oncol 1991, 9:1138-1150.

29. Goff BA, Sainz De La Cuesta R, Muntz HG, et al: Clear cell carcinoma of the ovary: a distinct histologic type with poor prognosis and resistance to platinum-based chemotherapy in stage III disease. Gynecol Oncol 1996 60:412-417

30. Sugiyama T, Yakushiji M, Nishida T, et al: Irinotecan (CPT-11) combined with cisplatin in patients with refractory or recurrent ovarian cancer. Cancer Lett 1998, 128:211-218.

31. Ho CM, Huang YJ, Chen TC, et al: Pure-type clear cell carcinoma of the ovary as a distinct histological type and improved survival in patients treated with paclitaxel-platinum-based chemotherapy in pure-type advanced disease. Gynecol Oncol 2004, 94:197-203.

32. Enomoto T, Kuragaki C, Yamasaki M: Is clear cell carcinoma and mucinous carcinoma of the ovary sensitive to combination chemotherapy with paclitaxel and carboplatin?. Proc Am Soc Clin Oncol 2003, 22(\#1797):447

33. Utsunomiya $\mathrm{H}$, Akahira J, Tanno S, et al: Paclitaxel-platinum combination chemotherapy for advanced or recurrent ovarian clear cell adenocarcinoma: a multicenter trial. Int J Gynecol Cancer 2006, 16:52-56.

34. Minagawa $Y$, Kigawa J, Ishihara $H$, et al: Synergistic enhancement of cisplatin cytotoxicity by SN-38, an active metabolite of CPT-11, for cisplatin-resistant HeLa cells. Jpn J Cancer Res 1994, 85:966-971.

35. Fukuda M, Nishio K, Kanzawa F, et al: Synergism between cisplatin and topoisomerase I inhibitors, NB-506 and SN-38, in human small cell lung cancer cells. Cancer Res 1996, 56:789-793.

36. Noda K, Nishiwaki Y, Kawahara M, et al: Irinotecan plus cisplatin compared with etoposide plus cisplatin for extensive small-cell lung cancer. $N$ Engl J Med 2002, 346:85-91.

37. Adachi S, Ogasawara T, Yamasaki N, et al: A pilot study of CPT-11 and cisplatin for ovarian clear cell adenocarcinoma. Jpn J Clin Oncol 1999, 29:434-437.

38. Kita T, Kikuchi Y, Kudoh $K$, et al: Exploratory study of effective chemotherapy to clear cell carcinoma of the ovary. Oncol Rep 2000, 7:327-331.

39. Takano M, Sugiyama T, Yaegashi N, et al: Progression-free survival and overall survival of patients with clear cell carcinoma of the ovary treated with paclitaxel-carboplatin or irinotecan-cisplatin: retrospective analysis. Int J Clin Oncol 2007, 12:256-260.

40. Takakura S, Takano M, Takahashi F, et al: Randomized phase II trial of paclitaxel plus carboplatin therapy versus irinotecan plus cisplatin therapy as first-line chemotherapy for clear cell adenocarcinoma of the ovary: a JGOG study. Int J Gynecol Cancer 2010, 20:240-247. 
41. http://www.gcig.igcs.org/files/JGOG3017_Protocol.pdf: accessed on April 16, 2012.

42. Parmar MK, Ledermann JA, Colombo N, et al: Paclitaxel plus platinumbased chemotherapy versus conventional platinum-based chemotherapy in women with relapsed ovarian cancer: the ICON4/AGOOVAR-2.2 trial. Lancet 2003, 361:2099-2106

43. Kikuchi Y, Kita T, Takano M, et al: Treatment options in the management of ovarian cancer. Expert Opin Pharmacother 2005, 6:743-754.

44. Crotzer DR, Sun CC, Coleman RL, et al: Lack of effective systemic therapy for recurrent clear cell carcinoma of the ovary. Gynecol Oncol 2007, 105:404-408.

45. Takano M, Sugiyama T, Yaegashi N, et al: Low response rate of second-line chemotherapy for recurrent or refractory clear cell carcinoma of the ovary: a retrospective Japan Clear Cell Carcinoma Study. Int J Gynecol Cancer 2008, 18:937-942.

46. Wilailak S, Linasmita V, Srisupundit S: Phase II study of high-dose megestrol acetate in platinum-refractory epithelial ovarian cancer. Anticancer Drugs 2001, 12:719-724.

47. Takano M, Kikuchi Y, Kudoh K, et al: Weekly administration of temsirolimus for heavily pretreated patients with clear cell carcinoma of the ovary: a report of six cases. Int J Clin Oncol 2011, 16:605-609.

48. Yoshino K, Enomoto T, Fujita M, et al: Salvage chemotherapy for recurrent or persistent clear cell carcinoma of the ovary: a single-institution experience for a series of 20 patients. Int I Clin Oncol in press, :- . in press.

49. Ho ES, Lai CR, Hsieh YT, et al: p53 mutation is infrequent in clear cell carcinoma of the ovary. Gynecol Oncol 2001, 80:189-193.

50. Okuda T, Otsuka J, Sekizawa A, et al: p53 mutations and overexpression affect prognosis of ovarian endometrioid cancer but not clear cell cancer. Gynecol Oncol 2003, 88:318-325.

51. Salani R, Kurman RJ, Giuntoli R 2nd, et al: Assessment of TP53 mutation using purified tissue samples of ovarian serous carcinomas reveals a higher mutation rate than previously reported and does not correlate with drug resistance. Int J Gynecol Cancer 2008, 18:487-491.

52. Hough $\mathrm{CD}$, Cho KR, Zonderman $\mathrm{AB}$, et al: Coordinately up-regulated genes in ovarian cancer. Cancer Res 2001, 61:3869-3876.

53. Tsuda H, Ito YM, Ohashi $Y$, et al: Identification of overexpression and amplification of ABCF2 in clear cell ovarian adenocarcinomas by CDNA microarray analyses. Clin Cancer Res 2005, 11:6880-6888.

54. Schwartz DR, Kardia SL, Shedden KA, et al: Gene expression in ovarian cancer reflects both morphology and biological behavior, distinguishing clear cell from other poor-prognosis ovarian carcinomas. Cancer Res 2002, 62:4722-4729.

55. Tsuchiya A, Sakamoto M, Yasuda J, et al: Expression profiling in ovarian clear cell carcinoma: identification of hepatocyte nuclear factor-1 beta as a molecular marker and a possible molecular target for therapy of ovarian clear cell carcinoma. Am J Pathol 2003, 163:2503-2512.

56. Kato N, Sasou S, Motoyama T: Expression of hepatocyte nuclear factor1 beta (HNF-1 beta) in clear cell tumors and endometriosis of the ovary. Mod Pathol 2006, 19:83-89.

57. Lee S, Garner El, Welch WR, et al: Over-expression of hypoxia-inducible factor 1 alpha in ovarian clear cell carcinoma. Gynecol Oncol 2007, 106:311-317.

58. Miyazawa M, Yasuda M, Fujita M, et al: Therapeutic strategy targeting the mTOR-HIF-1alpha-VEGF pathway in ovarian clear cell adenocarcinoma. Pathol Int 2009, 59:19-27.

59. Mabuchi S, Kawase C, Altomare DA, et al: mTOR is a promising therapeutic target both in cisplatin-sensitive and cisplatin-resistant clear cell carcinoma of the ovary. Clin Cancer Res 2009, 15:5404-5413.

60. Temsirolimus, Carboplatin, and Paclitaxel as First-Line Therapy in Treating Patients With Newly Diagnosed Stage III or Stage IV Clear Cell Ovarian Cance; http://clinicaltrials.gov/ct2/show/NCT01196429, accessed on April 16, 2012.

61. Sunitinib Malate in Treating Patients With Persistent or Recurrent Clear Cell Ovarian Cancer; http://clinicaltrials.gov/ct2/show/NCT00979992: accessed on April 16, 2012.

doi:10.1186/1756-9966-31-53

Cite this article as: Takano et al:: Clear cell carcinoma of the ovary: Is there a role of histology-specific treatment? Journal of Experimental \& Clinical Cancer Research 2012 31:53.

\section{Submit your next manuscript to BioMed Central and take full advantage of:}

- Convenient online submission

- Thorough peer review

- No space constraints or color figure charges

- Immediate publication on acceptance

- Inclusion in PubMed, CAS, Scopus and Google Scholar

- Research which is freely available for redistribution 